\title{
POSSIBILIDADES DO TRATO DA VARIACCÃO LINGUÍSTICA EM SALA DE AULA: UMA EXPERIÊNCIA COM OS PRINCÍPIOS DA SOCIOLINGUISTICA EDUCACIONAL
}

\author{
POSSIBILITIES OF TRACT OF CHANGE LANGUAGE IN THE CLASSROOM: AN \\ EXPERIENCE WITH THE PRINCIPLES OF EDUCATIONAL SOCIOLINGUISTICS
}

\author{
Elecy Rodrigues Martins \\ UERR \\ Nilmara Milena Gomes Maran \\ UFRR
}

\begin{abstract}
RESUMO: Roraima, por consequências históricas de sua formação institucional, possui uma população com características diversas, apresentando a pluralidade cultural como um atributo e, por consequência, uma variação linguística eminente e transportada para sala de aula. Nesse ambiente, a heterogeneidade de falares e pluralidade cultural são vistas como riqueza, mas também são motivadoras de preconceitos. Baseado nessa realidade, este trabalho busca relatar uma experiência de ensino em uma turma do 6응 ano do Ensino Fundamental de uma escola pública estadual em de Boa Vista-RR a respeito da variação linguística, e mais precisamente sobre concordância de número no sintagma nominal, devido ao seu valor sociossimbólico. Essa atividade foi desenvolvida durante o curso de Sociolinguística Educacional, parte integrante do projeto Pontes, sobre a coordenação geral da Professora Bortoni-Ricardo e tem o objetivo de tornar-se instrumento de reflexão sobre a mediação do professor diante da perspectiva de promoção da competência comunicativa do aluno.
\end{abstract}

PALAVRAS CHAVE: Concordância de número no sintagma nominal. Mediação pedagógica. Competência comunicativa.

ABSTRACT: Roraima, on the historical consequences of their institutional training, has a population with different characteristics, presenting cultural plurality as an attribute and therefore a variation eminent linguistic and transported to the classroom. In this environment, the diversity of dialects and cultural diversity are seen as wealth, but are also motivating prejudices. Based on this fact, this work seeks to relate an experience of teaching a class in the 6th grade of elementary school in a public school in Boa Vista-RR regarding linguistic variation, and more precisely on Concordance of Number in the Nominal Syntagma, because its symbolic value social. This activity was developed during the course of Sociolinguistics Education, part of the Bridges project on the overall coordination of Bortoni-Ricardo and aims to become an instrument of reflection on teacher mediation at the prospect of promoting communicative competence student.

KEYWORDS: Concordance of Number in the Nominal Syntagma. Mediation training. Communicative competence. 


\section{Revista do SELL}

v. $4, n^{\circ} .1$

ISSN: $1983-3873$

\section{Introdução}

O estado de Roraima possui como características a heterogeneidade de falares e a pluralidade cultural, consequências sócio-histórico-culturais decorrentes do seu processo de colonização e institucionalização. Além das pessoas de origem indígena local, o Estado é formado por migrantes vindos principalmente do Maranhão, Ceará, Piauí, Rio Grande do Norte, Amazonas, Pará, Rio Grande do Sul, Paraná e Rondônia (FREITAS, 2001, p. 39) e de todos os demais estados da federação, além de estrangeiros vindos pincipalmente dos países fronteiriços, Venezuela e Guiana Inglesa. (ver figura abaixo).

Essa região de fronteira apresenta aspectos particulares se comparada com as demais regiões fronteiriças do Brasil. Características linguísticas singulares como a existência de contato linguístico do português do Brasil com o espanhol da Venezuela, com a língua inglesa da Guiana e com as línguas indígenas presentes nessa região.

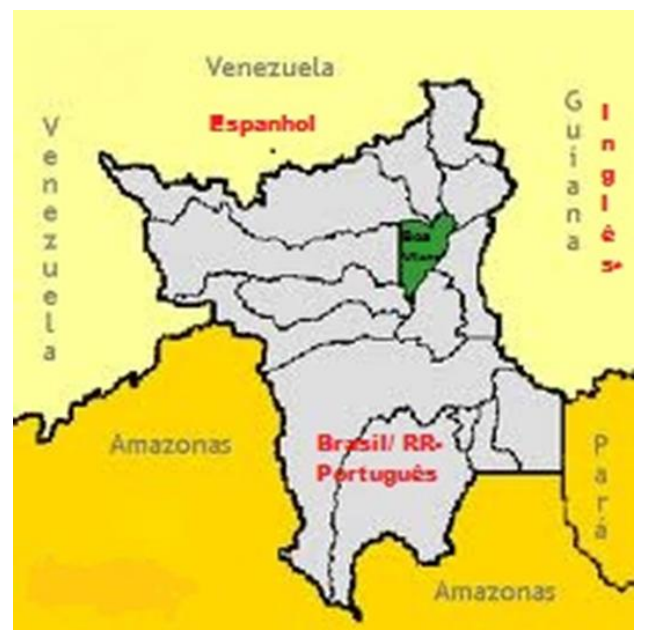

Fonte: http://www.mochileiro.tur.br/boavista.htm. Adaptado por Elecy R Martins.

Nesse processo migratório, essas pessoas trouxeram e ainda trazem consigo aquilo que sua terra ofereceu: seus hábitos alimentares, suas vestimentas, sua música, suas angústias, suas expectativas e seus hábitos linguísticos. Por consequência, a população desse estado apresenta uma variação linguística eminente.

É possível perceber, na fala de seus habitantes, variações diatópicas, típicas das mais diversas regiões brasileiras, tais como a do paraibano, do maranhense, do gaúcho, do carioca; e diastráticas que se referem às diferenças sociais e podem ser relacionadas 


\section{Revista do SELL}

v. $4, n^{\circ} .1$

ISSN: $1983-3873$

à escolarização, dentre outras razões. Essa heterogeneidade de falares e pluralidade cultural são vistas como riqueza, mas também são motivadoras de preconceitos.

A realidade linguística do Estado é transportada para sala de aula. Nesse ambiente encontramos falantes - professores e alunos - com hábitos linguísticos diferentes, vindos das mais diversas regiões brasileiras e estrangeiras, mais comumente vindos da Venezuela ou Guiana. É nesse contexto que professores, principalmente os de língua portuguesa, atuam, estejam eles preparados ou não para essa realidade.

Baseado nessa realidade, este trabalho tem o objetivo de relatar uma experiência de ensino em uma turma do $6^{\circ}$ ano do Ensino Fundamental de uma escola pública estadual em de Boa Vista-RR a respeito da variação linguística, e mais precisamente sobre concordância de número no sintagma nominal, devido ao seu valor sociossimbólico. Essa atividade foi desenvolvida durante o curso de Sociolinguística Educacional, parte integrante do projeto Pontes, sobre a coordenação geral da professora Bortoni-Ricardo, e teve como propósito tornar-se instrumento de reflexão sobre a mediação do professor diante da perspectiva de promoção da competência comunicativa do aluno.

\section{Bases para análise}

O termo competência comunicativa foi cunhada por Del Hymes (1972) para significar a capacidade de um falante "saber o que falar e como falar com quaisquer interlocutores, em qualquer circunstância" (apud BORTONI-RICARDO, 2004, p. 73). Portanto, este conceito inclui a noção de adequação como forma de monitorar o estilo tanto em situações cotidianas como em situações formais que pressupunham estresse comunicativo (GIVON, 1979 apud BORTONI-RICARDO, 2005, p. 63).

A promoção dessa competência responde ao objetivo do ensino da língua materna e visa a oportunizar os alunos conhecimentos sobre várias situações de uso da língua em interação. Com intuito de promover essa competência nos alunos, a atividade proposta também visa a destacar a mediação docente na atuação com os seguintes princípios da Sociolinguística Educacional: a pedagogia culturalmente sensível que corresponde a todos os esforços cultivados pela escola com o intuito de acolher o aluno em todos os aspectos pertinentes à sua prática escolar e proporcionar ações que sejam capazes de diminuir os atritos que possam ser gerados nos processos comunicativos-; e os processos de andaimagens que, na sala de aula, correspondem às ações empregadas pelo 


\section{Revista do SELL}

v. $4, n^{\circ} .1$

ISSN: $1983-3873$

professor com o intuito de promover a compreensão e consequentemente a aprendizagem do que se propõe ensinar.

As atitudes pedagógicas da escola e, consequentemente, dos professores, quando pautados no conceito de pedagogia culturalmente sensível (Aculturally responsive pedagogy), podem, de forma mais eficaz, levar o aluno a superar dificuldades de ordem comunicativa. Esse conceito foi proposto por Erickson (1987) que considera a transformação da prática educativa rotina necessária, e a pedagogia culturalmente sensível um meio de transformação. Bortoni-Ricardo, citando Erickson, expõe que essa proposta pedagógica consiste num

tipo especial de esforço, empreendido pela escola, que pode reduzir as dificuldades de comunicação entre professores e alunos, desenvolvendo assim a confiança e prevenindo a gênese de conflitos que se movem rapidamente além dos mal-entendidos, (...) entre alunos e professores. (BORTONI-RICARDO, 2003, p. 131)

Dito de outra forma, correspondem a todos os esforços cultivados pela escola com o intuito de acolher o aluno em todos os aspectos pertinentes à sua prática escolar e proporcionar ações que sejam capazes de diminuir os atritos gerados nos processos comunicativos, conduzindo o aluno ao progresso escolar.

É natural que se espere do professor estratégias e atitudes facilitadoras da aprendizagem, de forma que o aluno tenha acesso a novos dados e consequentemente amplie seu conhecimento. Ao adotar a postura da pedagogia culturalmente sensível, o professor, como forma de intervenção, pode valer-se de atitudes como a andaimagem, (scaffolding do inglês), conceito desenvolvido nas bases da psicologia e da sociolinguística interacional e disseminado na literatura linguística por Courtney Cazden (1991)

Para a análise dos aspectos citados levaremos em consideração os seguintes indicativos:

a) Quando e como ocorre a promoção da competência comunicativa;

b) Onde e como ocorre o processo de andaimagem;

c) Onde e como ocorre a ação da pedagogia culturalmente sensível. 


\section{Revista do SELL}

v. $4, n^{\circ} .1$

ISSN: $1983-3873$

A descrição da aula em modelo de protocolo verbal (MAGALHÃES e MACHADO, 2012) tem a finalidade de proporcionar a explicitação dos eventos de mediação ocorridos durante o processo da aula.

A importância da abordagem da variação linguística na escola dá-se em razão de essa ser o modo como a língua é usada por diversos grupos sociais e, portanto, está intimamente relacionada ao valor social atribuído ao sujeito que a usa, ás relações de força linguística e ao capital linguístico ${ }^{1}$ (BOURDIEU, 2003). Em razão das várias possibilidades de variação, fez-se um recorte para abordar somente a variação de número do sintagma nominal, situando a variação no aspecto morfossintático da língua. Sobre essa variação Scherre afirma que

(...) a variação na concordância de número no português falado do Brasil, longe de ser restrito a uma região ou classe social específica, é característico de toda comunidade de fala brasileira, apresentando diferenças mais de grau do que de princípio, ou seja, as diferenças são mais relativas à quantidade de marcas de plural e não aos contextos linguísticos nos quais a variação ocorre. Dos trabalhos realizados, conclui-se, portanto, que o fenômeno da variação de número no português do Brasil pode ser caracterizado como um caso de variação linguística inerente, tendo em vista que ocorre em contextos linguísticos e sociais semelhantes e apresenta tendências sistemáticas de variação altamente previsíveis. (SCHERRE, 1994, p. 38)

Ainda sobre a concordância de número, Scherre \& Naro (2006, p. 108) dizem que "a variante explícita de plural é a variante de prestígio. A variante zero de plural, quando percebida, é julgada pela tradição e pelos falantes como índice de não saber falar", portanto, o domínio da variante explícita de plural configura grande valor social, motivo pelo qual a concordância de número nominal foi estabelecida como recorte deste trabalho.

\section{A mediação em foco}

Após verificar que o conhecimento dos alunos sobre o tema "variação linguística" pautava-se apenas no senso comum, constituído através de análises preconceituosas

\footnotetext{
${ }^{1}$ As relações de força linguística explicam porque determinados falantes exercem poder e domínio sobre outros na interação verbal e determinados produtos linguísticos recebem mais valor que outros. Capital linguístico remete ao conceito de mercado linguístico estabelecendo que "uma competência só tem valor quando existe um mercado para ela”. Ver (BOURDIEU, 2003) e (SOARES, 1988).
} 


\section{Revista do SELL}

v. $4, n^{\circ} .1$

ISSN: $1983-3873$

decorrentes do processo sócio-histórico de formação do estado de Roraima² ${ }^{2}$, propôs-se em uma turma do $6^{\circ}$ ano uma discussão geral sobre 0 tema que perpassou pelo multilinguismo no Brasil e pelas variações no Português Brasileiro (PB), com ênfase na concordância de número no sintagma nominal (SN).

Essa discussão é descrita em forma de protocolo. Nele, para facilitar a compreensão e determinar quem são os falantes, utilizamos PP para Professora Pesquisadora, A para Aluno, As para Alunos, e A1, A2, A3, e A4 para distinguir o alunos/falantes nos processos de interação. Os colchetes [...] indicam o recorte de certos momentos de fala, e os (::) entre as palavras como em - (Vá::rios) indicam o prolongamento da vogal, como segue:

\section{Protocolo 01}

\section{Evento: aula sobre variação linguística.}

1. PP - No Brasil, nós temos várias línguas, será?

2. As $-s i:: m$

3. As-nã::o

4. A1 - A não ser do estrangero que vin'a pra cá!

5. PP - Ah tá, mas e os índios? Eles falam português?

6. As - Não

7. As - Alguns

8. PP - Tem muitas tribos no Brasil, será?

9. As-Te::m

10.PP - Cada tribo fala uma língua, não fala?

11. A-Hanram

12.PP - Então, só tem o português ou tem muitas línguas?

13.As -Tem muitas línguas

\footnotetext{
${ }^{2}$ Com o advento da criação do Território Federal, o próprio Governo Federal tratou de estimular e organizar as migrações principalmente do nordeste e do sul do país. Estas migrações obedeciam às levas de imigrantes determinadas pelo Estado, incentivadas pela distribuição de terras para incentivo à agricultura e pecuária, de bens de consumo gratuitos, de alimentos, casas, etc. O garimpo, nas décadas de 80 e 90 , o propósito de transformação do Território Federal em Estado e a abertura de concursos públicos a partir do ano 2000 também foram fatores que incentivaram migrações para Roraima (FREITAS, 2001). Nas primeiras fases desse processo, os migrantes, em sua maioria eram nordestinos (maranhenses em maioria), de pouca ou nenhuma escolaridade e consequentemente, com hábitos linguísticos pertinentes a este contexto. A partir de então, formularam-se folcloricamente vários pré-conceitos, entre eles o linguístico, sobre nordestinos e principalmente sobre maranhenses.
} 


\section{Revista do SELL}

v. $4, n^{\circ} .1$

ISSN: $1983-3873$

\section{$[\ldots]$}

14.PP - O pessoal lá do Rio Grande do Sul fala igual ao pessoal aqui de Roraima?

15.As - Nã::O

16.PP - Alguém sabe uma diferença?

17.A - Eles falam meio assi::m, mei inrolado, assim.

18.PP - Meio enrolado?

19.0 pessoal lá do nordeste, lá da Paraíba, eles falam igual ao pessoal aqui de Roraima?

20.A - Não.

21.A1-Os maranhense também.

22.PP - Os maranhenses falam igual ao pessoal aqui de Roraima?

23.A - Fala Não!

\section{[...]}

24.PP- lá na minha cidade,[...] quem não estudou, quem não teve oportunidade de ir pra escola, fala assim: OS MENINO SAIU. Certo? Ele tá falando aqui de um menino ou de vários meninos?

25.As - Vá::rios

26.PP- Por que que vocês sabem que são vários?

27. A1 - Porque tem o 'OS' agora se fosse 'O MENINO' era só um.

28.PP - Exatamente!

29.PP - Mas quem é estudado, quem passou algum tempo na escola pode falar diferente, não é? OS MENINOS SAIRAM. (enquanto a PP escreve no quadro o alunos leem a frase escrita)

30.As - Os meninos saíram.

31. PP - Olha, na fala eles falam assim (a PP aponta para o quadro mostrando a variação não padrão: OS MENINO SAIU) E Quando vocês vão escrever? Como é que vocês escrevem?

32.As - Os meninos saí::ram.

33.PP - Porque, porque na fala você pode falar assim, mas na escrita tem que ser diferente?

(os alunos não conseguem responder)

34.A - Sei não!

35. PP - Quem é que sabe escrever? Quem já frequentou a?

36. A- Escola!

37. PP - Escola. Quem já teve uma educação mais formal. E, na escola, nós aprendemos a falar e a escrever de uma forma diferente daquela que nós temos em casa. Às vezes diferente, né?. Nós temos as variedades populares das pessoas que falam na rua, que estudaram, que não estudaram, e a variedade padrão. [...]

38.PP - O que é uma variedade padrão? Ela segue certas normas.

39. A-Regras.

40. PP - A escola, ela ensina a variedade popular ou a variedade padrão?

41.As - Popular

42.As - Padrão 


\section{Revista do SELL}

v. $4, n^{\circ} .1$

ISSN: $1983-3873$

43.PP - A escola tem que reconhecer as variedades populares. Por exemplo, tem aluno que vem pra escola que fala desse jeito (a PP aponta para o quadro mostrando a variação não padrão: OS MENINO SAIU ) não tem?

44.As - Te:::m.

45.A1 - É os analfabeto

46.PP - Não, são aqueles cujas famílias têm esse hábito. Né? De falar dessa forma.

47.A3 - Eu falo diferente, eu.

48.PP - Então eles vão aprender o que?

49. As - A falar certo.

50.PP - Vão aprender a variedade?

51.As - Popular.

52. As - Padrão.

53.A4 - Com tempo a pessoa se acostuma a não falar mais o maranhense. A minha mãe falava maranhense, mas ela mora aqui desde os onze anos e ela não fala assim.

54.PP- Ela se habituou com a nova forma de falar. Então, nós somos assim. Nós nos adaptamos. A gente fala do jeito que a família da gente fala, que os amigos da gente fala lá na rua. Mas quando a gente começa frequentar a escola, nós vamos adquirindo novas formas que correspondem à variedade...

55. As -padrão

56. PP - padrão, né isso?

57.[...]

\subsection{A análise da mediação pedagógica}

A ação de análise do fazer docente é um recurso primoroso ao trabalho do professor porque the possibilita avaliar o processo de ensino em ato reflexivo da ação docente, cumprindo assim o ciclo do processo planejamento/execução e avaliação. Dito de outro modo, garante o cumprimento do processo ação-reflexão-ação. De modo mais específico, visa a avaliar se o objetivo da aula foi cumprido e indica a necessidade de pensar em possíveis ajustes.

\subsubsection{O desenvolvimento da competência comunicativa}

A promoção da competência comunicativa ocorre quando o professor proporciona a possibilidade aos alunos de conhecerem melhor a língua que usam e a língua que escutam nas redes sociais que têm acesso. Um importante momento desse processo na 


\section{Revista do SELL}

v. $4, n^{\circ} .1$

ISSN: $1983-3873$

aula descrita ocorre quando a professora relaciona o modo de falar ao processo de escolarização do sujeito. Os turnos a seguir revelam esse aspecto:

24. PP- lá na minha cidade,[...] quem não estudou, quem não teve oportunidade de ir pra escola, fala assim: OS MENINO SAIU. Certo? Ele tá falando aqui de um menino ou de vários meninos?

29. PP - Mas quem é estudado, quem passou algum tempo na escola pode falar diferente, não é? OS MENINOS SAIRAM. (enquanto a PP escreve no quadro o alunos leem a frase escrita)

30. As - Os meninos saíram.

31. PP - Olha, na fala eles falam assim (a PP aponta para o quadro mostrando a variação não padrão) E Quando vocês vão escrever?Como é que vocês escrevem?

40. PP- A escola, ela ensina a variedade popular ou a variedade padrão?

Essa questões lançadas em sala tinham o objetivo de instigar nos alunos a análise da língua e suas variações através dos conhecimentos já adquiridos pelos alunos para assim perceberem suas formas e contextos de uso.

De acordo com Bortoni- Ricardo (2005, p 175) [...] "a variação linguística é um dos principais recursos à disposição do falante para ampliar a eficácia da comunicação e a identidade social do indivíduo". Nestes termos, a escola desempenha papel fundamental na aquisição de novas possibilidades de uso da língua, principalmente no que se refere às variações de prestígio, ou seja, a variação padrão e consequentemente de inserção social do aluno. Esse papel da escola já é previsto nos documentos oficiais de regulamentação/orientação de ensino como os PCN como segue:

[...] a aula deve ser o espaço privilegiado de desenvolvimento de capacidade intelectual e linguística dos alunos, oferecendo-Ihes condições de desenvolvimento de sua competência discursiva. Isso significa aprender a manipular textos escritos variados e adequar o registro oral às situações interlocutivas, o que, em certas circunstâncias, implica usar padrões mais próximos da escrita. (BRASIL, 1998, p. 30)

Assim, com a abordagem acima, pretendeu-se também ratificar que a escolarização é fator preponderante para 0 desenvolvimento da competência comunicativa, dando aos alunos instrumentos que possibilitem a eles variar o uso da língua conforme a necessidade. Pretendeu-se ainda destacar o papel da escola no 


\section{Revista do SELL \\ v. $4, n^{\circ} .1$ \\ ISSN: $1983-3873$}

acolhimento do aluno e de sua cultura e, paralelamente a este acolhimento, promover aprendizagens ainda não adquiridas, bem como a conscientização do valor social que possui cada escolha linguística que fazemos.

\subsubsection{A concordância de número no $\mathrm{SN}$}

Além de buscar inserir elementos que corroborassem a construção de conceitos sobre variação linguística, o que se pretendia em relação à concordância de número no SN era analisar o conhecimento do aluno sobre sua língua no que corresponde à viabilidade e gramaticalidade, ou seja, seu conhecimento internalizado, independente do conhecimento transmitido pela escola. Para tanto, utilizou-se um teste de recepção expondo um aspecto da concordância de número correspondente à variação do português não padrão, como em OS MENINO SAIU.

24. PP- lá na minha cidade,[...] quem não estudou, quem não teve oportunidade de ir pra escola, fala assim: OS MENINO SAIU. Certo? Ele tá falando aqui de um menino ou de vários meninos?

25 As - Vá::rios

26. PP- Por que é que vocês sabem que são vários?

27. A1 - Porque tem o 'OS' agora se fosse ‘O MENINO' era só um.

28. $P P$ - Exatamente!

29. PP - Mas quem é estudado, quem passou algum tempo na escola pode falar diferente, não é? OS MENINOS SAIRAM. (enquanto a PP escreve no quadro o alunos leem a frase escrita)

30. As - Os meninos saíram.

31. PP - Olha, na fala eles falam assim (a PP aponta para o quadro mostrando a variação não padrão) E Quando vocês vão escrever? Como é que vocês escrevem?

32. As - Os meninos saí::ram.

Com estes turnos, pode-se inferir que os alunos reconhecem o uso da estrutura do SN “Os menino”, apesar desta pertencer a variações linguísticas menos prestigiadas, já que exibe uma estrutura cujo primeiro elemento apresenta variante explícita 'oS' e 0 segundo a variantes zero 'menino $\varnothing$ '. Pode-se também perceber que eles reconhecem a gramaticalidade do sintagma, justificando, de forma satisfatória em (27), que o fato de o determinante "Os" possuir marca explícita de plural já é suficiente para determinar que a quantidade de meninos é superior a um, revelando, naturalmente, que conhecem os 


\section{Revista do SELL \\ v. $4, n^{\circ} .1$ \\ ISSN: $1983-3873$}

conceitos de economia linguística e de redundância. Desta forma a construção "OS MENINO SAIU" é reconhecida como viável nos termos de Hymes (1972)

Essa percepção é conduzida pela professora através de atitudes de andaimagens (CAZDEN, 1988), quando conduz o aluno a perceber a estrutura gramatical e seu significado através de questionamentos como em (29) , e quando os faz perceber a necessidade de monitoração no uso da língua em suportes e contextos diferentes na fala e na escrita, como nos turnos (29) e (31).

29. Mas quem é estudado, quem passou algum tempo na escola pode falar diferente, não é? OS MENINOS SAIRAM. (enquanto a PP escreve no quadro os alunos leem a frase escrita)

31. PP - Olha, na fala eles falam assim (a PP aponta para o quadro mostrando a variação não padrão: OS MENINO SAIU) E Quando vocês vão escrever? Como é que vocês escrevem?

Já nos turnos abaixo, o mesmo aluno, que elaborou tão precisamente a justificativa (27) para o uso de estruturas não pertencentes à variação padrão, produziu a fala em 45.

\section{A1 - É os analfabeto!}

43. PP - A escola tem que reconhecer as variedades populares. Por exemplo, tem aluno que vem pra escola que fala desse jeito (a PP aponta para o quadro mostrando a variação não padrão: OS MENINO SAIU) não tem?

44. As - Te::m.

45. A1-É os analfabeto!

Nota-se nesta fala uma contradição entre o que é ideal e o que é a prática linguística, pois o mesmo aluno que classifica como "analfabetos" aqueles que não possuem elementos que viabilizem o uso da concordância de número previsto na variação padrão, também não o faz, mostrando que apesar de reconhecer o valor social deste aspecto da língua não possui mecanismos que viabilizem a prática da monitoração linguística.

\subsubsection{O processo de andaimagem}

O processo de andaimagem é inerente à ação do professor quando assume a perspectiva de tornar-se mediador da aprendizagem dos alunos. Nesse papel, ele utiliza- 


\section{Revista do SELL \\ v. $4, n^{\circ} .1$ \\ ISSN: $1983-3873$}

se do mecanismo da andaimagem para provocar no aluno a compreensão sobre algo ou alguma situação de aprendizagem, fornecendo-lhe pistas de contextualização (GUMPERZ, 2003 apud BORTONI-RICARDO, 2004, p.02) para que ele alcance o objetivo pretendido.

Esse processo pode ser observado no turno 14. da aula quando diz $P$ - O pessoal lá do Rio Grande do Sul fala igual ao pessoal aqui de Roraima? Assim, pretendia-se apontar que no $\mathrm{PB}$, além de outras, há variações que decorem da origem geográfica do falante, o que é bem comum em Roraima, tendo em vista que esse é um estado formado basicamente pelo processo de migração, que trouxe como uma consequência, talvez a mais visível, a variação linguística. Com esta mesma pretensão seguiram-se os turnos: 19. PP - O pessoal lá do nordeste, lá da Paraíba eles falam igual ao pessoal aqui de Roraima?" 22. PP - Os maranhenses falam igual ao pessoal aqui de Roraima?

\subsubsection{A utilização da pedagogia culturalmente sensível}

A utilização da pedagogia culturalmente sensível representa um modo de ação do professor em correspondência ao conhecimento que tem sobre o relativismo cultural (BORTONI-RICARDO, 2008) que defende a igualdade entre as culturas, onde a língua é a sua fiel representação. Entender a língua na sua relação com a cultura é extremamente importante ao professor, porque essa compreensão o possibilita a estar mais propenso a promover a competência comunicativa do aluno por meio de situações de interação linguística vivenciadas pelas diversas comunidades de fala.

(55) PP - Ela se habituou com a nova forma de falar. Então, nós somos assim. Nós nos adaptamos. A gente fala do jeito que a família da gente fala, que os amigos da gente fala lá na rua. Mas quando a gente começa frequentar a escola, nós vamos adquirindo novas formas que correspondem à variedade...

A professora nesse momento acolhe o turno do aluno reconhecendo a veracidade na informação dada por ele, ao mesmo tempo em que aproveita a oportunidade para ampliar a informação dada, relacionando a língua às condições de interação nas quais os sujeitos estão envolvidos.

Esse mesmo procedimento é observado nos turnos a seguir. Vejamos: 


\section{Revista do SELL}

v. $4, n^{\circ} .1$

ISSN: $1983-3873$

1. PP - No Brasil, nós temos várias línguas, será?

2. As - si::m

3. As - nã::0

4. A1 - A não ser do estrangero que vin'a pra cá!

5. PP - Ah tá, mas e os índios? Eles falam português?

6. As - Nã::0

7. As-Alguns

8. PP - Tem muitas tribos no Brasil, será?

9. As-Te::m

10. PP - Cada tribo fala uma língua, não fala?

11. A-Hanram

12. P - Então, só tem o português ou tem muitas línguas?

13. As-Tem muitas línguas

[...]

Nestes turnos, a professora persegue 0 objetivo de fazer os alunos compreenderem a variedade de línguas existentes no Brasil, desmistificando a noção de pais monolíngue. Para isso ela fornece pistas de contextualização para que os alunos cheguem à compreensão esperada. Quando a resposta não corresponde ao esperado, a professora ratifica a fala do aluno, como na expressão "ah tà..." mas em seguida fornece outra pista - mas e os índios? Eles falam português? - para que o aluno perceba esse fato e tire as próprias conclusões.

Apesar de buscar a prática da pedagogia culturalmente sensível, percebeu-se que algumas vezes ela tornou-se ineficaz como se pode observar nos turnos a seguir.

43.PP - A escola tem que reconhecer as variedades populares. Por exemplo, tem aluno que vem pra escola que fala desse jeito (a PP aponta para o quadro mostrando a variação não padrão: OS MENINO SAIU) não tem?

44.As - Te::m.

45.A1 - É os analfabeto

46.PP - Não, são aqueles cujas famílias têm esse hábito. Né? De falar dessa forma.

47.A3 - Eu falo diferente, eu.

48.PP - Então eles vão aprender o que?

49.As - A falar certo.

50.PP - Vão aprender a variedade?

51.As - Popular.

52.As - Padrão. 


\section{Revista do SELL}

v. $4, n^{\circ} .1$

ISSN: $1983-3873$

53.A4 - Com tempo a pessoa se acostuma a não falar mais o maranhense. A minha mãe falava maranhense ${ }^{3}$, mas ela mora aqui desde os onze anos e ela não fala assim.

54.PP. Ela se habituou com a nova forma de falar. Então, nós somos assim. Nós nos adaptamos. $A$ gente fala do jeito que a família da gente fala, que os amigos da gente fala lá na rua. Mas quando a gente começa frequentar a escola, nós vamos adquirindo novas formas de se expressar que correspondem à variedade...

56.As -padrão

57.PP - padrão, né isso?

58.[...]

As informações que a professora buscava obter dependiam de explicações mais amplas que demandavam tempo, para que houvesse a desmistificação de alguns preconceitos, e para o entendimento de que as produções de algumas variações são o resultado da interação cultural, dos hábitos familiares e não da inexistência do processo de escolarização.

Em (53) nota-se, pela fala do aluno A4, o preconceito já arraigado na sociedade roraimense. Tais preconceitos são estabelecidos principalmente pela falta de informação, motivo pelo qual se torna de fundamental importância na formação do aluno o trato da pluralidade cultural brasileira, e uma de suas principais consequências: a variação linguística.

\section{Uma consideração}

É impossível negar a existência da variação das línguas e o seu ensino pautado nas teorias sociolinguísticas deve considerar essas variações como riqueza, fazendo com que os alunos adquiram conhecimentos sobre elas, de forma a possibilitar 0 desenvolvimento da capacidade de monitoração no uso da linguagem em quaisquer

\footnotetext{
3 As correntes migratórias advindas do Maranhão, inicialmente eram basicamente compostas por lavradores, produtores rurais e suas famílias que, impossibilitados de produzir em terras cada vez mais escassas, viam em Roraima a possibilidade de vida nova. Como afirma Freitas (2001, p. 123) "foram os maranhenses que vieram pra cá em maior número, em especial os do Vale dos rios Mearim e Pindaré, mais especificamente das cidades de Bacabal, Santa Inês, Lago da Pedra, Pedreiras, Pio XII e cidades próximas. No Maranhão essa região vem se tornando eminentemente de pecuária (...) e, com isso, a terra de agricultura vem sendo, constantemente, diminuída causando a expulsão dos colonos e agricultores". Essas pessoas tinham geralmente pouca escolaridade, portanto apresentavam e ainda apresentam características culturais e linguísticas ignorantemente pouco apreciadas.
} 


\section{Revista do SELL}

v. $4, n^{\circ} .1$

ISSN: $1983-3873$

momentos, ou situações em que ela for requisitada. Portanto, há a necessidade da escola e do professor trabalharem nesse sentido e promover o conhecimento das normas sociais de uso da língua.

A atuação do professor de língua portuguesa é de fundamental importância, dada a sua possibilidade de transformar as variações linguísticas presentes em sala de aula em material fomentador de conhecimento linguístico dos alunos, transformando 0 conhecimento empírico em teórico. Essa ação do professor possibilita o entendimento das variações linguísticas como formas diferentes de realização da língua, assinalando-as como resultados socioculturais e, portanto, como consequência e componente da riqueza cultural do Estado.

Pautadas na utilização da pedagogia culturalmente sensível, tendo os processos de andaimagens como instrumento metodológico, abordagens positivas em relação à variação linguística podem tornar-se eficazes no desenvolvimento da competência comunicativa dos alunos gerando a consciência de uma ação de monitoração linguística e fornecendo-Ihes outras possibilidades de uso da língua, consequentemente propiciando maiores condições de letramento dos alunos. Entretanto, isso requer um planejamento consciente dos objetivos que se deseja e dos meios para alcançá-los, ações que nem sempre são perseguidas por nós professores.

\section{BIBLIOGRAFIA}

BORTONI-RICARDO, S. M. Processos interativos em sala de aula e a pedagogia culturalmente sensível. Cuiabá: Polifonia EDUFMT, 2003. № 07 p.119-136.

BORTONI-RICARDO, Stella Maris. Educação em língua materna: a sociolinguística na sala de aula. São Paulo: Parábola, 2004.

São Paulo: Parábola, 2005.

Nós cheguemu na escola, e agora? Sociolinguística e educação.

O tratamento do conceito de Relativismo Cultural nas séries iniciais da escolarização. In.: COX, M. I. P. (org.). Que português é esse? Vozes em conflito. São Carlos: Pedro \& João Editores/ Cuiabá EdUFMT, 2008, p. 67-82

FERNANDES DE SOUSA, Maria Alice. Andaimes e pistas de contextualização: um estudo do processo interacional em uma sala de alfabetização. Universidade de Brasília, 2004. 


\section{Revista do SELL \\ v. $4, n^{\circ} .1$ \\ ISSN: $1983-3873$}

BOURDIEU, Pierre. Questões de sociologia. Tradução de Miguel Serras Pereira. Fim de século-Edições, Sociedade Unipessoal, LDA., Lisboa, 2003.

BRASIL. Secretaria de Educação Fundamental. Parâmetros curriculares nacionais: terceiro e quarto ciclos do ensino fundamental: língua portuguesa. Brasília: MEC/SEF, 1998. http://portal.mec.gov.br/seb/arquivos/pdf/ em 07/06/2011.

CAZDEN, C. La interacción entre iguales: procesos cognoscitivos, en: El discurso en el aula. El lenguaje de la enseñanza y del aprendizaje, Paidós, Barcelona. (1991), Cap. 7.

ERICKSON, F. Transformation and school success: the politics and culture of educational achievement. in Anthropology \& Education Quarterly, Vol. 18(4) pp 335-56, December 1987.

FREITAS, Aimberê. Geografia e História de Roraima. Boa Vista-RR: DLM, 2001

HYMES, D. On Communicative Competence, in: PRIDE, J. B. e HOLMES, J. (Orgs.) Sociolinguistics. Harmondsworth: Penguin,1972.

MAGALHÃES, R. \& MACHADO, V.R. leitura e interação no enquadre de protocolos verbais. In BORTONI-RICARDO, S. M \& et al. Leitura e mediação pedagógica. São Paulo: Parábola, 2012.

SCHERRE, M. M. P. Aspectos da concordância de número no português do Brasil. Revista Internacional de Língua Portuguesa (RILP) - Norma e Variação do Português. Associação das Universidades de Língua Portuguesa. 12:37-49. dez. de 1994. Disponível em: http://www.ai.mit.edu/projects/dm/bp/scherre94-number.pdf. Acessado em 23/01/2012.

NARO, Anthony J. Mudança sem mudança: a concordância de número no português do brasileiro. Scripta, Belo Horizonte, Editora PUCMINAS v. 9, n. 18 , p. 107-129, 1ำ sem. 2006.

SOARES, Magda. Linguagem e escola. Uma perspectiva social. 6 Ed. São Paulo: Ática, 1988. (Série princípios) 